\title{
Children With Metabolically Healthy Obesity: A Review
}

\author{
Rade Vukovic ${ }^{1,2 * t}$, Tiago Jeronimo Dos Santos ${ }^{3 \dagger}$, Marina Ybarra ${ }^{4,5 t}$ and Muge Atar ${ }^{6 \dagger}$ \\ ${ }^{1}$ Department of Pediatric Endocrinology, Mother and Child Healthcare Institute of Serbia "Dr Vukan Cupic", Belgrade, Serbia, \\ ${ }^{2}$ School of Medicine, University of Belgrade, Belgrade, Serbia, ${ }^{3}$ Department of Preventive Medicine and Public Health, \\ Universidad Autónoma de Madrid, Madrid, Spain, ${ }^{4}$ Research Center of Sainte Justine University Hospital, Université de \\ Montréal, Montreal, QC, Canada, ${ }^{5}$ Centre Armand-Frappier, Institut National de la Recherche Scientifique, Université du \\ Québec, Laval, QC, Canada, ${ }^{6}$ Department of Pediatric Endocrinology, School of Medicine, Demirel University, Isparta, Turkey
}

\section{OPEN ACCESS}

Edited by: Lucia Pacifico,

Sapienza University of Rome, Italy

Reviewed by:

Norbert Stefan,

University of Tübingen, Germany

Giovanni Tarantino,

University of Naples Federico II, Italy

*Correspondence:

Rade Vukovic radevukovic9@gmail.com

†These authors have contributed equally to this work

Specialty section: This article was submitted to Pediatric Endocrinology, a section of the journal Frontiers in Endocrinology

Received: 17 October 2019 Accepted: 26 November 2019 Published: 10 December 2019

Citation:

Vukovic R, Dos Santos TJ, Ybarra M and Atar M (2019) Children With Metabolically Healthy Obesity: A Review. Front. Endocrinol. 10:865. doi: 10.3389/fendo.2019.00865
Children with "metabolically healthy obesity" $(\mathrm{MHO})$ are a distinct subgroup of youth with obesity, who are less prone to the clustering of cardiometabolic risk factors. Although this phenotype, frequently defined by the absence of metabolic syndrome components or insulin resistance, was first described during the early 1980s, a consensus-based definition of pediatric $\mathrm{MHO}$ was introduced only recently, in 2018. The purpose of this review was to concisely summarize current knowledge regarding the $\mathrm{MHO}$ phenomenon in youth. The prevalence of $\mathrm{MHO}$ in children varies from 3 to $87 \%$, depending on the definition used and the parameters evaluated, as well as the ethnicity and the pubertal status of the sample. The most consistent predictors of $\mathrm{MHO}$ in youth include younger age, lower body mass index, lower waist circumference, and lower body fat measurements. Various hypotheses have been proposed to elucidate the underlying factors maintaining the favorable $\mathrm{MHO}$ phenotype. While preserved insulin sensitivity and lack of inflammation were previously considered to be the main etiological factors, the most recent findings have implicated adipokine levels, the number of inflammatory immune cells in the adipose tissue, and the reduction of visceral adiposity due to adipose tissue expandability. Physical activity and genetic factors also contribute to the $\mathrm{MHO}$ phenotype. Obesity constitutes a continuum-increased risk for cardiometabolic complications, which is less evident in children with $\mathrm{MHO}$. However, some findings have highlighted the emergence of hepatic steatosis, increased carotid intima-media thickness and inflammatory biomarkers in the $\mathrm{MHO}$ group compared to peers without obesity. Screening should be directed at those more likely to develop clustering of cardiometabolic risk factors. Lifestyle modifications should include behavioral changes focusing on sleep duration, screen time, diet, physical activity, and tobacco smoke exposure. Weight loss has also been associated with the improvement of insulin sensitivity and inflammation. Further investigative efforts are needed in order to elucidate the mechanisms which protect against the clustering of cardiometabolic risk factors in pediatric obesity, to provide more efficient, targeted treatment approaches for children with obesity, and to identify the protective factors preserving the $\mathrm{MHO}$ profile, avoiding the crossover of $\mathrm{MHO}$ to the phenotype with metabolically unhealthy obesity.

Keywords: obesity, children, metabolically healthy obesity, metabolic syndrome, pediatric obesity 


\section{INTRODUCTION}

The global epidemic of childhood obesity, with the accompanying rise in the prevalence of endocrine, metabolic, and cardiovascular comorbidities in youth, represents one of the most important public health issues of the modern world $(1-4)$. The earlier occurrence and increase in the prevalence of both pediatric obesity and metabolic syndrome (MS) leads to a potential decline in life expectancy, meaning that the youth of today could be the first generation to live shorter lives than their parents $(2,4-6)$.

In the context of the childhood obesity pandemic, a distinct subgroup of youth with obesity less prone to the development of metabolic disturbances, called "metabolically healthy obese" (MHO), has come into focus $(7,8)$. Despite having obesity, individuals with MHO display a "favorable" metabolic profile, with preserved insulin sensitivity, normal blood pressure and glucose regulation, normal lipids and liver enzymes, as well as a normal hormonal, inflammation, and immune profile (9-13). First described and investigated in the population of adults with obesity, the MHO phenomenon has also been extensively studied and confirmed in young people with obesity $(4,7,13)$.

Although MHO status might not necessarily translate into lower mortality, and can crossover to "metabolically unhealthy obese" (MUO) phenotype during puberty, defining the MHO subpopulation within the youth with obesity is of high importance in order to elucidate the mechanisms protecting against the clustering of cardiometabolic risk factors, and for its clinical, preventive, and therapeutic decision-making implications $(4,7,13-17)$. For example, the clear distinction between youth with MHO and MUO could prove useful in providing more efficient and targeted treatment approaches for both of these groups of children with obesity $(4,13,18)$. The purpose of this review was to provide a concise summary of the current knowledge regarding $\mathrm{MHO}$ phenomenon in childhood and adolescence, including definition, prevalence, predictors, underlying mechanisms, treatment, outcomes, and implications for future research and clinical practice.

\section{MHO IN CHILDHOOD: CRITERIA AND DEFINITIONS USED}

Although MHO phenotype was first described during the early 1980s, and is frequently defined (on the basis of known metabolic abnormalities associated with obesity) by the absence of MS components and/or preserved insulin sensitivity, a consensusbased definition of pediatric MHO was introduced only recently, in $2018(4,7,13,19,20)$. Consequently, all the knowledge gained from the previous research is limited by the variety of definitions and criteria used for defining MHO. Despite the differences in the definitions used to identify MHO children, all available data undeniably confirms that a significant proportion of the youth with obesity displays a "favorable" metabolic phenotype [Figure 1; $(4,18)$ ].

Until now, within the population of youth with obesity, children with MHO have been identified based either on the absence of MS components, preserved insulin sensitivity, or by various combinations of these criteria $(8,14,16,18,21-24)$. Definitions have varied widely amongst different studies, even when defining obesity (or overweight) as sine qua non for youth with MHO. The cutoff values for obesity have differed amongst studies from the 85th to 97th percentile of body mass index (BMI) according to the Centers for Disease Control and Prevention (CDC) growth charts, while other researchers have used the World Health Organization (WHO) criteria, waist circumference (WC) or waist-to-height-ratio $(4,13)$. The definitions of the MHO phenotype in youth with obesity used in previous studies were most commonly based on: (a) absence of cardiometabolic risk factors (16, 25-27), (b) presence of $\leq 1$ cardiometabolic risk factor $(24,27,28)$, (c) presence of $\leq 2$ cardiometabolic risk factors (29), (d) other criteria such as preserved insulin sensitivity or a combination of the above criteria $(14,30,31)$. In all these studies, there has been great variation in the parameters considered as cardiometabolic risk factors [including high density lipoprotein (HDL), triglycerides, total cholesterol, low density lipoprotein (LDL), fasting plasma glucose, hemoglobin A1c (HbAlc), fasting plasma insulin, various indices of insulin sensitivity, etc.], with even more variation in the cutoff values defined using either absolute or percentile values, further contributing to the heterogeneity of the MHO definition (13). Furthermore, in addition to MS components or insulin sensitivity, it has been observed in several studies that individuals with MHO display other favorable phenotypic characteristics, such as the absence of hepatic steatosis, lower levels of liver enzymes, interleukin 6 and C-reactive protein compared with the rest of the population with obesity $(22,32-36)$.

Finally, in 2018, Damanhoury et al. proposed the first international consensus-based definition of MHO [Table 1; (13)]. The consensus was achieved to define obesity based on the BMI standard deviation score (BMI-SDS) $>+2$ SD using the WHO growth charts $(13,37)$. In respect of the definition, consensus was achieved that only children with obesity fulfilling all of the cardiometabolic criteria shown in Table 1 should be classified as with MHO (13). For the measure of glycemia criterion, no consensus was achieved, although the fasting plasma glucose with cutoff of $\leq 100 \mathrm{mg} / \mathrm{dl}$ ( $\leq 5.6 \mathrm{mmol} / \mathrm{l})$, was the criterion for euglycemia most commonly used in previous studies of MHO in children (13). Hopefully, this definition could become a first step to standardization of the MHO phenotype in youth.

One of the advantages of using the consensus-based definition proposed by Damanhoury et al. is the fact that most of the cutoff values are based on cutoffs provided by the International Diabetes Federation (IDF) definition of MS in youth, and are therefore widely used and known by clinicians and researchers dealing with pediatric obesity. The use of IDF MS cutoff values should facilitate comparison with future studies, and these fasting measures have also been shown to be reliable and valid for use in the population of youth with obesity $(2,13,31)$. More importantly, this consensus-based definition is simple to use in the clinical setting, and is based on a Delphi process generated consensus of an international panel of 46 experts. This makes it more likely to be accepted by the majority of researchers in the field, which is probably the most important aspect in 

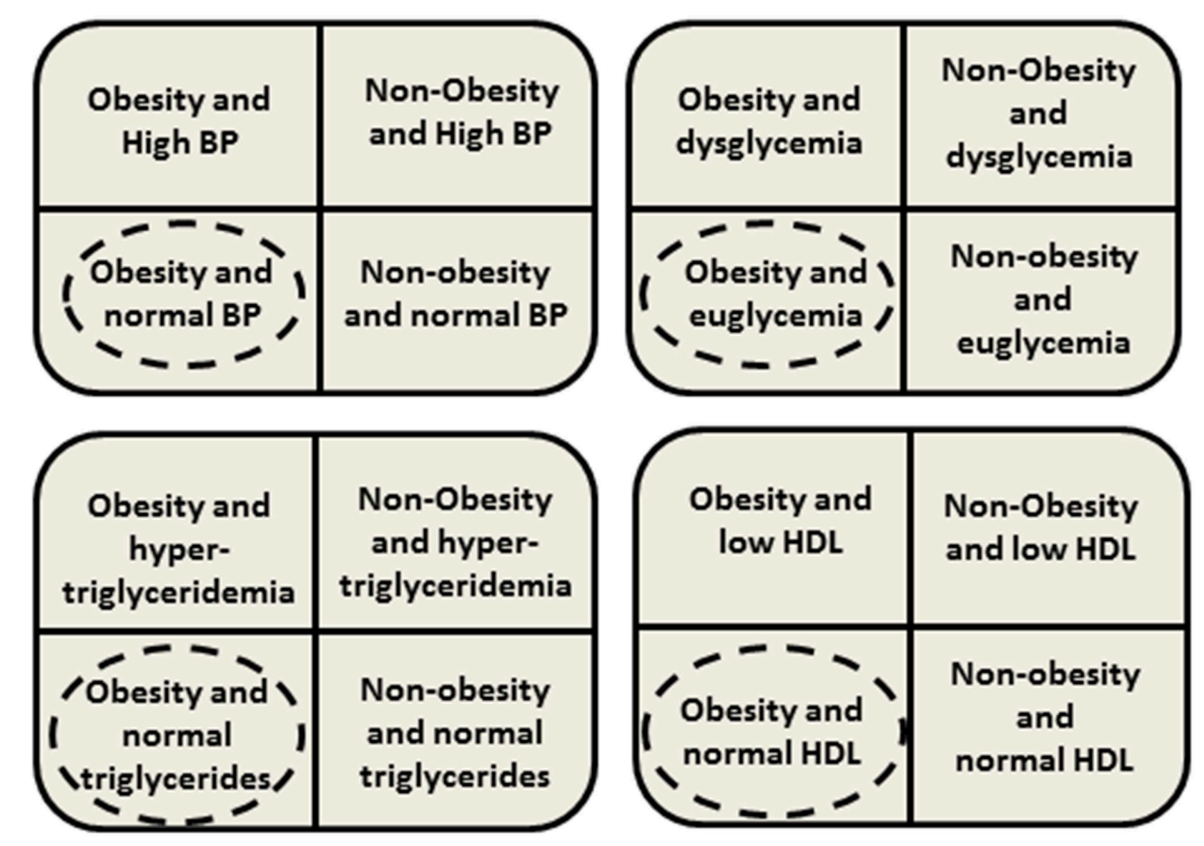

FIGURE 1 | Presence or absence of clustering cardiometabolic risk factors. Dashed circles mean phenotype classified as metablically healthy obesity (MHO) in youth. $\mathrm{BP}$, blood pressure; HDL, high density lipoprotein.

TABLE 1 | Consensus-based definition of $\mathrm{MHO}$ in children (13).

Only children with all of the following criteria fulfilled are classified as $\mathrm{MHO}$

$\begin{array}{ll}\text { BMI-SDS } & >+2 \mathrm{SD} \text { (using the WHO growth charts) } \\ \text { HDL } & >40 \mathrm{mg} / \mathrm{dl}(>1.03 \mathrm{mmol} / \mathrm{l}) \\ \text { Triglycerides } & \leq 150 \mathrm{mg} / \mathrm{dl}(\leq 1.7 \mathrm{mmol} / \mathrm{l}) \\ \text { Blood pressure } & \leq 90 \text { th percentile } \\ \text { (systolic and diastolic) } & \\ \text { A measure of glycemia } & \text { Fasting plasma glucose } \leq 100 \mathrm{mg} / \mathrm{dl}(\leq 5.6 \mathrm{mmol} / \mathrm{l}) \\ & \text { (the most commonly used euglycemia criterion) }\end{array}$

$\overline{M H O}$, metabolically healthy obesity; BMI-SDS, body mass index standard deviation score; $H D L$, high density lipoprotein.

order to avoid further diversification in defining the MHO youth (13).

It should be noted, that the consensus-based MHO definition lacks important indicators of "metabolic health," such as indicators of hepatic steatosis, immune, and inflammation markers. In addition, insulin resistance, a component considered to have a central role in the development of the obesity related cardiometabolic risk factors, is not included in this definition $(2,13)$. These shortcomings of the consensus definition should not be overlooked, although it would not be reasonable to expect availability of all these parameters in every future study of youth with MHO. One possible solution would be to use the consensus definition in all future studies of MHO in children as a starting point for a universal MHO definition. This approach would maximize the comparability of prevalence rates and clinical findings between studies, with the possibility of adding additional markers of "metabolic health" when feasible, while also presenting the findings based solely on the consensus definition of $\mathrm{MHO}$.

The ideal definition of MHO should include (in addition to the MS components) the degree of visceral adiposity, insulin sensitivity, markers of hepatic steatosis, inflammatory, and immune parameters, although as yet, no consensus has been reached on the use of these parameters (or their cutoff values) in defining $\mathrm{MHO}$ (4). Thus, the inclusion of these parameters in the $\mathrm{MHO}$ definition at the present time would only aggravate the diversification in defining the MHO phenotype in children, leading both to difficulties in comparison of MHO prevalence rates, and to different findings between studies (31).

\section{PREVALENCE AND PREDICTORS OF MHO IN CHILDHOOD}

The estimated prevalence of children with MHO has differed significantly in previous studies, in large part due to the various definitions used. As already stated, until 2018 there was no consensus regarding the definition of $\mathrm{MHO}$ in pediatrics and the criteria used for defining both the obesity and MHO/MUO status varied widely. Moreover, the groups studied were significantly distinct from one another (regarding gender, age, ethnicity, degree of obesity, etc.). Bearing all this in mind, the overall estimated prevalence of metabolically healthy phenotype in children of all weight status varied from 7 to $21 \%$, whereas the prevalence of $\mathrm{MHO}$ among overweight and obese children varied from 3 to $87 \%(15,16,18,21,22,25,27,28,31,38-56)$. 
Even though the protecting factors keeping the children with $\mathrm{MHO}$ on the healthy side of the metabolic phenotype, despite the increase in adiposity, have not yet been fully elucidated, many authors have tried to identify the predictors of MHO status. The adiposity rebound, the early increase in BMI-SDS occurring in some children between the ages of 3 and 7 years, is known to be a significant risk factor for later obesity (57). A recent study assessing the prevalence of $\mathrm{MHO}$ among 31-year old adults from the Northern Finland Birth Cohort 1966 found that at the age of adiposity rebound, females with $\mathrm{MHO}$ were five and a half months younger and males with $\mathrm{MHO}$ were 4 months older, compared to the MUO group. Study findings demonstrated that the time of adiposity rebound might also have a role in defining the future cardiometabolic risk status in adulthood (58).

Pubertal status also plays a significant role in the development of both MHO and MUO phenotypes in youth with obesity. Puberty is a period of dynamic physiological changes, including a well-described physiological decrease in insulin sensitivity (59). A longitudinal study conducted with 2017 children with obesity over the course of 1 year showed that entering puberty doubled the risk for switching from MHO to the MUO phenotype, whereas changing from the mid to late pubertal stage nearly tripled the likelihood for crossing over from MUO to MHO, according to the results of multiple logistic regression analyses adjusted for age, sex, and changes of BMI-SDS (15). These findings highlight the importance of distinguishing physiological and pathological aspects of puberty within the MHO/MUO phenotypes in youth. Other studies have demonstrated that being in the earlier stages of pubertal development was a predictor for being metabolically healthy $(15,16)$. Diet and lifestyle habits may also contribute significantly to the MHO profile during puberty. A Canadian longitudinal study of 48 participants with MHO, who were followed up for 2 years as they entered puberty, showed that every additional daily portion of fruit and vegetables decreased the risk of converting to metabolically unhealthy obesity by $39 \%$ (60). The same study showed that more hours of screen time, and diet low in protein and high in saturated fat and sugar-sweetened beverages, were associated with the development of the MUO profile (60).

In an attempt to address the predictors of the MHO phenotype in youth, a recent large-scale, cross-sectional Chinese study of 7,926 children and adolescents aged 7-16 years in all weight ranges found that those with the metabolically healthy obesity phenotype were younger, and had lower BMI-SDS, WC, and body fat measurements (38). Another study conducted in Saudi Arabia with more than a thousand children with obesity also found that a younger age, lower BMI-SDS, and WC measurements, and female gender were predictors of MHO in children (41). A recent study conducted in Germany of a cohort of 246 children aged 7-18 years with overweight and obesity demonstrated that children with MHO were younger, had lower BMI-SDS and lower WC measurements, and lower plasma levels of uric acid and C-peptide, but were more likely to be male (42).

Among children and adolescents with overweight and obesity, the most consistent predictors for being metabolically healthy, as described in the previous studies were lower WC measurements $(16,18,21,22,25,28,38,41,48,49,51,55,61,62)$, lower
BMI-SDS $(22,25,38,41,42,44,48-50,63)$, younger age $(15,16$, $25,38,41,42,48,50)$, and lower body fat measurements $(21,23$, 25, 38, 44, 61-63). Nevertheless, the findings of several studies have also implicated additional potential predictors of $\mathrm{MHO}$. Dietary patterns such as higher fruit and vegetable intake $(60,63)$, less protein intake (49), lower junk food consumption (50), lower fat intake (18), and lower frequency of soft drinks consumption (51) were associated with MHO phenotype. Likewise, lifestyle habits (e.g., less sedentary time) (27, 50, 64), higher levels of moderate and moderate-to-vigorous physical activity (18, $27,49)$, and walking to school were also associated with a favorable metabolic profile (51). Sleep indicators have also been investigated and according to a study by Nasreddine et al., the weekly frequency of daytime napping was associated with the MHO profile (41). A South Korean study found that very short sleep duration $(<5 \mathrm{~h})$ when compared to a group with normal sleep duration $(8-10 \mathrm{~h})$, increased the risk of being metabolically unhealthy, independently of weight status (46).

Socio-economic features, such as having parents with a better socioeconomic status $(51,63)$ were found to be protective, in addition to higher birth weight (51), having generalized rather than central or combined obesity (65), lower waist-to-height ratio (25) and having a higher appendicular skeletal muscle mass in boys (66). The absence of Acanthosis nigricans (44, 48, 51) and laboratory markers of lower insulin resistance $(16,21,28$, $31,44,48,61)$ as well as a lower degree of hepatic steatosis $(22,62)$ have also been investigated and shown to be predictors of $\mathrm{MHO}$ phenotype. In respect of other serum markers, decreased serum levels of ferritin and hemoglobin (67), osteonectin, retinol binding protein 4 (RBP-4), and leptin/adiponectin ratio $(21,26$, 40) have been associated with the MHO phenotype.

\section{MECHANISMS OF DEVELOPMENT OF METABOLIC DISTURBANCES IN PEDIATRIC OBESITY}

Various hypotheses have been proposed to elucidate the underlying factors leading to the development of metabolic disturbances in pediatric obesity, and the mechanisms preserving the favorable MHO profile. The development of insulin resistance has been suggested as one of the main underlying etiological factors leading to metabolic disturbances in obesity (68, 69). Insulin affects the metabolic function of many organs including muscle tissue, adipose tissue, and the intestine, with a consequent multitude of metabolic disturbances arising with the development of insulin resistance (68). One of the most significant consequences of obesity is the development of impaired glucose tolerance (IGT) and type 2 diabetes (T2D). The transition from IGT to T2D in adults is estimated to occur within 5-10 years, although this process may be accelerated in some individuals $(70,71)$. Weiss et al. showed that weight gain in children was closely associated with deterioration of glucose regulation assessed using the oral glucose tolerance test (OGTT). They also found that an increased amount of adipose tissue, even if the BMI remained constant due to increase in height, was associated with a decrease in insulin sensitivity and progression 
to IGT from previously normal glucose regulation during OGTT (72). Findings from several studies have also confirmed that some children with obesity, and their relatives, display a low insulin secretion capacity to maintain euglycemia in insulinresistant states (73-77). Therefore, a hereditary $\beta$-cell capacity to overcome significant insulin resistance may be considered as one of the potential mechanisms underlying completely normal glucose regulation in children with $\mathrm{MHO}$.

Adipose tissue inflammation is considered to be one of the main factors underlying the development of insulin resistance in obesity (78-80). It is well-known that adipose tissue is a highly active endocrine and metabolic organ, sensing energy requirements, and secreting hormones (adipokines) and cytokines (anti-inflammatory and pro-inflammatory cytokines) (81). The balance between pro-inflammation and anti-inflammation shifts to the direction of inflammation due to an increase in the amount of adipose tissue accumulated in the adipocytes, although the exact mechanisms triggering inflammation are still being investigated (82). Increased concentrations of free fatty acids in adipocytes could activate endoplasmic reticulum and homeostatic stress and inflammation via the pro-inflammatory cytokines c-Jun N-terminal kinase (JNK) and nuclear factor-kappa B (NF $\kappa$ B) (81). Activation of these cytokines promotes monocyte chemoattractant protein-1 (MCP-1) response which leads to the migration of monocytes to the adipocyte tissue. MCP-1 is a key factor for monocyte migration to adipocytes, further cytokine release and the eventual development of atherosclerosis (83). Activation of the inflammatory cascade leads to the activation of serine kinases and the release of other molecules, such as galectin-3 and leukotriene B4 (LTB4), which directly decrease insulin sensitivity, thus resulting in insulin resistance $(84,85)$. There is also evidence suggesting that inflammation in obesity could be triggered by higher circulating levels of lipopolysaccharides (LPS), which are produced by gram negative bacteria in the intestine, in individuals with obesity. In obesity, increased intestinal permeability leads to the increased entry of LPS into the systemic circulation. These LPS are believed to trigger the inflammation process via activation of Toll-like receptor 4 (TLR4) (86). Studies have also shown the importance of CD4, CD8, T-helper 1, and T-helper 2 cells in the development of inflammation in obesity, with alterations in numbers of these immune cells influencing the inflammation status in both humans and mice (87-89).

The distribution of adipose tissue has a critical role in the metabolic health status. The lipids in the human body are stored mainly in the subcutaneous adipose tissue compartment. There is evidence that increased ratio of the abdominal subcutaneous adipose tissue to total body fat mass is associated with the metabolically unhealthy phenotype, while the increase in the gluteofemoral subcutaneous adipose tissue seems to be positively associated with $\mathrm{MHO}(90,91)$. Additionally, when the storage capacity in the subcutaneous adipose tissue is exceeded, lipids are stored in the form of ectopic depositions in non-adipose tissue, such as muscle and liver, separate from the adipose tissue compartment. Several studies have shown that ectopic adipose tissue depositions in the liver, i.e., fatty liver, is significantly stronger predictor of MUO phenotype compared to the other ectopic fat deposition locations, which supports the important role of non-alcoholic fatty liver disease (NAFLD) in the development of the metabolically unhealthy phenotype $(36,92-$ 96). However, in the obesity spectrum, there are individuals able to expand their subcutaneous adipose tissue without increasing the visceral fat content, which leads to preserved insulin sensitivity and the MHO phenotype (12).

Adipokines synthesized in adipocytes from different adipose tissues (e.g., adiponectin and leptin), may contribute to the metabolically healthy or unhealthy status (36, 97-99). Higher adiponectin levels have a protective influence and are associated with preserved insulin sensitivity in adolescents (40, 100). Several studies have shown an association of single nucleotide polymorphisms (SNPs) in the adiponectin gene with the development of T2D (101). Weight loss interventions and female gender have also been found to be related with high adipokine levels (102-104). However, increased levels of other adipokines, such as leptin, omentin, vaspin, resistin, and retinol binding protein 4 (RBP4) are associated with the development of obesity-related metabolic disturbances $(105,106)$. Adipokines synthesized from visceral fat, especially from intrahepatic adipose tissue, have been associated with the MUO phenotype (36, 97-99). Adipocyte hyperplasia and hypertrophy has also been associated with obesity-related metabolic disturbances (107). As a result of the increased fat deposition in adipocytes, various hormones and cytokines are secreted, causing recruitment of pre-adipocytes and adipocyte remodeling (108). Adipocyte remodeling occurs as a result of the harmonious interplay of many factors, with proliferator-activated receptor $\gamma$ (PPAR $\gamma)$ playing the most important role (109). There is evidence that PPAR $\gamma$ could decrease the level of inflammation and insulin resistance, thus preventing metabolic deterioration (110). Moreover, the adipocyte hypertrophy and increased lipolysis lead to the leakage of free fatty acids, with smaller adipocytes having a higher lipogenesis/lipolysis ratio, which contributes to insulin resistance (111).

The liver plays a major role in both carbohydrate and lipid metabolism through several metabolic pathways, with the ectopic accumulation of lipids in the liver causing NAFLD and having the strongest effect on the metabolic profile (107, $112,113)$. Genome wide studies have identified genes linked to the hepatic fat accumulation, also known as NAFLD genes (114). Similar to the adipose tissue, liver tissue also secretes inflammatory cells and cytokines (hepatokines) which contribute to the metabolically unfavorable profile in $\operatorname{NAFLD}(94,115,116)$. NAFLD is associated with the accumulation of ceramides and diacylglycerols, leading to insulin resistance via insulin receptors and signaling pathways (117). In the state of insulin resistance in NAFLD, insulin is unable to suppress the hepatic glucose production with the worsening of the glycemic control, and at the same time lipogenesis continues, further contributing to the atherogenic lipid profile in NAFLD with increased risk of cardiovascular complications (118-121).

Genetic factors also play a role in the development of $\mathrm{MHO}$ and MUO phenotypes in youth with obesity. Recently published genome wide association studies have shown the 
relationship between some genetic loci and BMI (122, 123), adipose tissue distribution (visceral or subcutaneous) (124), and leptin levels (125). The insulin receptor substrate 1 locus (IRS1) has been found to be associated with increased body adipose tissue content, but a decreased cardiometabolic risk, thus it is considered to be a gene associated with the MHO phenotype (126). On the other hand, loci such as fat mass- and obesityassociated (FTO) and near sprouty homolog 2 (SPRY2) have been found to be associated with a higher cardiometabolic risk (126). Similar to the IRS1 locus effects, other variants (COBLL1/GRB14) have also been found to be associated with MHO profile despite increased body fat percentage, possibly due to favorable fat distribution (subcutaneous vs. visceral), with other loci (PLA2G6, TOMM40) potentially associated with MHO phenotype being studied (126-128).

\section{TREATMENT AND OUTCOMES OF MHO IN CHILDHOOD}

If not diagnosed early, prevented and treated, obesity in children and adolescents leads to the development of T2D, hypertension, dyslipidemia, atherosclerosis, and consequently a higher incidence of cardiovascular premature death in adulthood $(6,129)$. Although this section aims to analyze screening and therapeutic strategies for youth with obesity in respect to their metabolically healthy/unhealthy status, it is important to be aware that obesity represents a continuum gradient of risk for cardiometabolic diseases, and that this young population may benefit from early prevention and treatment as long as it is a problem likely to persist in adulthood $(13,129)$.

Although children with $\mathrm{MHO}$ are usually defined as being without traditional cardiometabolic risk factors within the MS definition, several studies have detected the presence of other features among this population, such as: hepatic steatosis, increased carotid intima-media thickness, and inflammatory biomarkers, as well as higher degree of visceral fat accumulation, higher birth weight, adipose cell size, and different gene expression-encoding markers in adipose tissue (4, 8, 130-134). The diverse characteristics found in children with MHO may indicate they pursue a different metabolic phenotype compared to their peers of normal weight $(7,18)$. The data assessing NAFLD and its influence on the crossover from MHO to MUO, although with growing importance, are scarce in the pediatric age and yet inconclusive $(4,135,136)$. Therefore, it is important to identify the group of children and adolescents with $\mathrm{MHO}$ who would benefit the most from early detection and intervention (13). Longitudinal studies have shown discrepancies in the results concerning the stability of the MHO/MUO status from childhood to the adulthood, depending largely on the length of assessment $(15,58)$. Thus, it is possible that previous crosssectional studies and studies that did not take the pubertal stage into consideration have provided limited results (6). On the other hand, findings from long term studies have indicated that $\mathrm{MHO}$ status is more stable in adulthood (i.e., children and adolescents are more likely to remain $\mathrm{MHO}$ if they reach adulthood as $\mathrm{MHO}$ ) (30). In the study by Li et al., these children with MHO did not have increased carotid-artery atherosclerosis compared with normal weight children, when assessed in adulthood (30). However, they presented with increased frequency of other cardiometabolic risk factors in adulthood, such as higher blood pressure levels and insulin resistance. These results suggest that all youth with obesity, including children and adolescents with MHO, might benefit from the early detection of obesity and weight-loss intervention programs (30).

The development or deterioration of cardiometabolic risk factors in children with $\mathrm{MHO}$ could potentially be prevented using specific measures such as low-intensity exercise. It is plausible that metabolic deterioration and crossover to MUO could be avoided in youth with $\mathrm{MHO}$ if a modest weight reduction is achieved or weight gain prevented (4). Although only studied in adults with MUO, besides the amount of weight loss, fatty liver at baseline was found to predict the response of conversion from MUO to a metabolically healthy phenotype $(136,137)$. Thus, by stratifying youth with obesity into groups at relatively lower and higher risk (MHO vs. MUO), the traditional one-size-fits-all treatment approach in managing obesity could be avoided. On the other hand, the continuum gradient of risk development for cardiometabolic diseases explains the importance of proper screening and an early start of treatment in both MHO and MUO children, although the metabolic profile of $\mathrm{MHO}$ individuals of pediatric age is almost indistinguishable from that of lean individuals (9). There is a possibility that MHO children may require less frequent follow-up or less intensive treatment, or possibly a different treatment approach compared to their MUO peers. However, this precondition needs to be evaluated in future studies, and in the meantime $\mathrm{MHO}$ children should be treated as all children with obesity, with special attention paid to the possibility of a crossover to MUO during puberty.

The management of children with $\mathrm{MHO}$ should not differ from the management of any child with obesity and therefore should emphasize preventive strategies, such as the promotion of a healthy lifestyle, especially targeting those with early onset obesity or rapid weight gain (60). In general, adults with obesity may respond differently to dietary and physical activity interventions for weight loss, and there is a hypothesis that MHO individuals may not metabolically benefit from these interventions (9). However, there are no findings to date, supporting this hypothesis in the population of youth with MHO. It has also been observed that children and adolescents are more likely to preserve their MHO status the less sedentary they are and the more time they spend in moderate-to-vigorous physical activities (27). Promoting a healthy diet should also be in the focus of preventive strategies. Although sometimes contradictory, several studies have shown that youth with MHO who ate fewer daily portions of fruits and vegetables, less meat, and had a higher intake of saturated fat were more likely to become MUO $(18,51,60)$.

More studies are required to clarify the effects of different therapeutic approaches for the MHO profile in childhood. Most of the current data available is derived from studies performed in adults, and results from longitudinal studies of youth with obesity (both $\mathrm{MHO}$ and MUO) will hopefully help 
to identify appropriate intervention strategies for children with obesity, according to their metabolic health status. Promising research linking $\mathrm{MHO}$ patients and additional cardiometabolic risk factors such as NAFLD, inflammatory biomarkers and carotid intima-media thickness, although not currently included in either MS or MHO consensus criteria, will be useful to identify and manage both $\mathrm{MHO}$ and MUO alike.

\section{CONCLUSIONS}

In conclusion, the use of a single/universal definition of $\mathrm{MHO}$ in childhood is highly beneficial for advancement in the field. We recommend use of the international consensus-based definition proposed by Damanhoury et al. to define the MHO phenotype in youth with obesity. When accessible, additional measures of "metabolic health" can also be included. This is crucial in order to have comparable results and further our understanding of the MHO phenomenon in children and adolescents. More data is needed in order to indentify the parameters which have the highest ability to predict clinically significant outcomes.

Future studies will improve our understanding of the prevalence, predictors and protective factors in $\mathrm{MHO}$, as well as the underlying mechanisms leading to the crossover from $\mathrm{MHO}$ to MUO during puberty. The MHO status should be defined and controlled for during longitudinal interventional studies, in order to account for possible differences in treatment outcomes

\section{REFERENCES}

1. Wang Y, Lobstein T. Worldwide trends in childhood overweight and obesity. Int J Pediatr Obes. (2006) 1:11-25. doi: 10.1080/17477160600 586747

2. Zimmet P, Alberti KG, Kaufman F, Tajima N, Silink M, Arslanian S, et al. The metabolic syndrome in children and adolescents - an IDF consensus report. Pediatr Diabetes. (2007) 8:299-306. doi: 10.1111/j.1399-5448.2007. 00271.x

3. Cali AM, Caprio S. Obesity in children and adolescents. J Clin Endocrinol Metab. (2008) 93(11 Suppl. 1):S31-6. doi: 10.1210/jc.2008-1363

4. Bluher S, Schwarz P. Metabolically healthy obesity from childhood to adulthood - does weight status alone matter? Metabolism. (2014) 63:1084-92. doi: 10.1016/j.metabol.2014.06.009

5. Olshansky SJ, Passaro DJ, Hershow RC, Layden J, Carnes BA, Brody J, et al. A potential decline in life expectancy in the United States in the 21st century. N Engl J Med. (2005) 352:1138-45. doi: 10.1056/NEJMsr0 43743

6. Juonala M, Magnussen CG, Berenson GS, Venn A, Burns TL, Sabin MA, et al. Childhood adiposity, adult adiposity, and cardiovascular risk factors. $N$ Engl J Med. (2011) 365:1876-85. doi: 10.1056/NEJMoa1010112

7. Primeau V, Coderre L, Karelis AD, Brochu M, Lavoie ME, Messier V, et al. Characterizing the profile of obese patients who are metabolically healthy. Int J Obes. (2011) 35:971-81. doi: 10.1038/ijo.2010.216

8. Weiss R, Taksali SE, Dufour S, Yeckel CW, Papademetris X, Cline G, et al. The "obese insulin-sensitive" adolescent: importance of adiponectin and lipid partitioning. J Clin Endocrinol Metab. (2005) 90:3731-7. doi: $10.1210 /$ jc. $2004-2305$

9. Karelis AD. Metabolically healthy but obese individuals. Lancet. 2008 372:1281-3. doi: 10.1016/S0140-6736(08)61531-7

10. Karelis AD, St-Pierre DH, Conus F, Rabasa-Lhoret R, Poehlman ET. Metabolic and body composition factors in subgroups of obesity: compared to the rest of the population with obesity. This could influence the development of targeted preventive and treatment strategies for youth with obesity with or without cardiometabolic risk factors in the future. Until then, the same therapeutic approaches and weight goals should be used in children with $\mathrm{MHO}$, with the emphasis on the prevention and promotion of healthy lifestyle habits.

\section{AUTHOR CONTRIBUTIONS}

RV conceptualized the manuscript, drafted the sections regarding background, and definitions of MHO. MY drafted the section regarding prevalence and predictors. MA drafted the section regarding mechanisms. TD drafted the section regarding the treatment and outcomes. All authors reviewed and revised the manuscript and approved the final version.

\section{ACKNOWLEDGMENTS}

We would like to acknowledge the European Society of Paediatric Endocrinology (ESPE) for bringing all of us together. Without ESPE Winter School and DOM School, this collaboration would have never happened. RV would also like to acknowledge the mentorship of Prof. Dr. Dragan Zdravkovic, who introduced RV to the field of $\mathrm{MHO}$, clinical research and pediatric endocrinology in general, thanking him for the knowledge and guidance. what do we know? J Clin Endocrinol Metab. (2004) 89:2569-75. doi: 10.1210/jc.2004-0165

11. Sims EA. Are there persons who are obese, but metabolically healthy? Metabolism. (2001) 50:1499-504. doi: 10.1053/meta.2001.27213

12. Bluher M. The distinction of metabolically 'healthy' from 'unhealthy' obese individuals. Curr Opin Lipidol. (2010) 21:38-43. doi: 10.1097/MOL.0b013e3283346ccc

13. Damanhoury S, Newton AS, Rashid M, Hartling L, Byrne JLS, Ball GDC. Defining metabolically healthy obesity in children: a scoping review. Obes Rev. (2018) 19:1476-91. doi: 10.1111/obr.12721

14. Vukovic R, Mitrovic K, Milenkovic T, Todorovic S, Soldatovic I, SipeticGrujicic S, et al. Insulin-sensitive obese children display a favorable metabolic profile. Eur J Pediatr. (2013) 172:201-6. doi: 10.1007/s00431-012-1867-5

15. Reinehr T, Wolters B, Knop C, Lass N, Holl RW. Strong effect of pubertal status on metabolic health in obese children: a longitudinal study. J Clin Endocrinol Metab. (2015) 100:301-8. doi: 10.1210/jc.2014-2674

16. Vukovic R, Milenkovic T, Mitrovic K, Todorovic S, Plavsic L, Vukovic A, et al. Preserved insulin sensitivity predicts metabolically healthy obese phenotype in children and adolescents. Eur J Pediatr. (2015) 174:1649-55. doi: 10.1007/s00431-015-2587-4

17. Kiess W, Penke M, Sergeyev E, Neef M, Adler M, Gausche R, et al. Childhood obesity at the crossroads. J Pediatr Endocrinol Metab. (2015) 28:481-4. doi: 10.1515/jpem-2015-0168

18. Prince RL, Kuk JL, Ambler KA, Dhaliwal J, Ball GD. Predictors of metabolically healthy obesity in children. Diabetes Care. (2014) 37:1462-8. doi: $10.2337 / \mathrm{dc} 13-1697$

19. Andres R. Effect of obesity on total mortality. Int J Obes. (1980) 4:381-6.

20. Sims EA. Mechanisms of hypertension in the syndromes of obesity. Int $J$ Obes. (1981) 5(Suppl. 1):9-18.

21. Weghuber D, Zelzer S, Stelzer I, Paulmichl K, Kammerhofer D, Schnedl W, et al. High risk vs. "metabolically healthy" phenotype in juvenile obesity - neck subcutaneous adipose tissue and serum uric acid are 
clinically relevant. Exp Clin Endocrinol Diabetes. (2013) 121:384-90. doi: 10.1055/s-0033-1341440

22. Senechal M, Wicklow B, Wittmeier K, Hay J, MacIntosh AC, Eskicioglu $\mathrm{P}$, et al. Cardiorespiratory fitness and adiposity in metabolically healthy overweight and obese youth. Pediatrics. (2013) 132:e85-92. doi: 10.1542/peds.2013-0296

23. Mangge H, Zelzer S, Puerstner P, Schnedl WJ, Reeves G, Postolache TT, et al. Uric acid best predicts metabolically unhealthy obesity with increased cardiovascular risk in youth and adults. Obesity. (2013) 21:E71-7. doi: 10.1002/oby.20061

24. Camhi SM, Waring ME, Sisson SB, Hayman LL, Must A. Physical activity and screen time in metabolically healthy obese phenotypes in adolescents and adults. J Obes. (2013) 2013:984613. doi: 10.1155/2013/984613

25. Aldhoon-Hainerova I, Hainer V, Zamrazilova H. Impact of dietary intake, lifestyle and biochemical factors on metabolic health in obese adolescents. Nutr Metab Cardiovasc Dis. (2017) 27:703-10. doi: 10.1016/j.numecd.2017.05.002

26. Aldhoon-Hainerova I, Zamrazilova H, Hill M, Hainer V. Insulin sensitivity and its relation to hormones in adolescent boys and girls. Metabolism. (2017) 67:90-8. doi: 10.1016/j.metabol.2016.10.005

27. Cadenas-Sanchez C, Ruiz JR, Labayen I, Huybrechts I, Manios Y, Gonzalez-Gross M, et al. Prevalence of metabolically healthy but overweight/obese phenotype and its association with sedentary time, physical activity, and fitness. J Adolesc Health. (2017) 61:107-14. doi: 10.1016/j.jadohealth.2017.01.018

28. Heinzle S, Ball GD, Kuk JL. Variations in the prevalence and predictors of prevalent metabolically healthy obesity in adolescents. Pediatr Obes. (2016) 11:425-33. doi: 10.1111/ijpo.12083

29. Camhi SM, Whitney Evans E, Hayman LL, Lichtenstein AH, Must A. Healthy eating index and metabolically healthy obesity in U.S. adolescents and adults. Prev Med. (2015) 77:23-7. doi: 10.1016/j.ypmed.2015.04.023

30. Li S, Chen W, Srinivasan SR, Xu J, Berenson GS. Relation of childhood obesity/cardiometabolic phenotypes to adult cardiometabolic profile: the Bogalusa Heart Study. Am J Epidemiol. (2012) 176(Suppl. 7):S142-9. doi: 10.1093/aje/kws236

31. Bervoets L, Massa G. Classification and clinical characterization of metabolically "healthy" obese children and adolescents. J Pediatr Endocrinol Metab. (2016) 29:553-60. doi: 10.1515/jpem-2015-0395

32. D'Adamo E, Cali AM, Weiss R, Santoro N, Pierpont B, Northrup V, et al. Central role of fatty liver in the pathogenesis of insulin resistance in obese adolescents. Diabetes Care. (2010) 33:1817-22. doi: 10.2337/dc10-0284

33. Marini MA, Succurro E, Frontoni S, Hribal ML, Andreozzi F, Lauro R, et al. Metabolically healthy but obese women have an intermediate cardiovascular risk profile between healthy nonobese women and obese insulin-resistant women. Diabetes Care. (2007) 30:2145-7. doi: 10.2337/dc07-0419

34. Karelis AD, Faraj M, Bastard JP, St-Pierre DH, Brochu M, Prud'homme $\mathrm{D}$, et al. The metabolically healthy but obese individual presents a favorable inflammation profile. J Clin Endocrinol Metab. (2005) 90:4145-50. doi: 10.1210/jc.2005-0482

35. Shin MJ, Hyun YJ, Kim OY, Kim JY, Jang Y, Lee JH. Weight loss effect on inflammation and LDL oxidation in metabolically healthy but obese (MHO) individuals: low inflammation and LDL oxidation in MHO women. Int $J$ Obes. (2006) 30:1529-34. doi: 10.1038/sj.ijo.0803304

36. Stefan N, Kantartzis K, Machann J, Schick F, Thamer C, Rittig $\mathrm{K}$, et al. Identification and characterization of metabolically benign obesity in humans. Arch Intern Med. (2008) 168:1609-16. doi: 10.1001/archinte.168.15.1609

37. World Health Organization. Obesity and Overweight. (2017). Available online at: http://www.who.int/mediacentre/factsheets/fs311/en/ (accessed June 2019).

38. Chen F, Liu J, Yan Y, Mi J, China Child and Adolescent Cardiovascular Health (CCACH) Study Group. Adolescent cardiovascular health study group. abnormal metabolic phenotypes among urban chinese children: epidemiology and the impact of DXA-measured body composition. Obesity. (2019) 27:837-44. doi: 10.1002/oby.22426

39. Heshmat R, Hemati Z, Payab M, Hamzeh SS, Motlagh ME, Shafiee G, et al. Prevalence of different metabolic phenotypes of obesity in Iranian children and adolescents: the CASPIAN V study. J Diabetes Metab Disord. (2018) 17:211-21. doi: 10.1007/s40200-018-0363-5

40. Fu J, Li Y, Esangbedo IC, Li G, Feng D, Li L, et al. Circulating osteonectin and adipokine profiles in relation to metabolically healthy obesity in Chinese children: findings from BCAMS. J Am Heart Assoc. (2018) 7:e009169. doi: 10.1161/JAHA.118.009169

41. Nasreddine L, Tamim H, Mailhac A, AlBuhairan FS. Prevalence and predictors of metabolically healthy obesity in adolescents: findings from the national "Jeeluna" study in Saudi-Arabia. BMC Pediatr. (2018) 18:281. doi: $10.1186 / \mathrm{s} 12887-018-1247-\mathrm{z}$

42. Rocha E, Vogel M, Stanik J, Pietzner D, Willenberg A, Korner A, et al. Serum uric acid levels as an indicator for metabolically unhealthy obesity in children and adolescents. Horm Res Paediatr. (2018) 90:19-27. doi: $10.1159 / 000490113$

43. Farello G, Antenucci A, Stagi S, Mazzocchetti C, Ciocca F, Verrotti A. Metabolically healthy and metabolically unhealthy obese children both have increased carotid intima-media thickness: a case control study. BMC Cardiovasc Disord. (2018) 18:140. doi: 10.1186/s12872-01 8-0874-5

44. Margolis-Gil M, Yackobovitz-Gavan M, Phillip M, Shalitin S. Which predictors differentiate between obese children and adolescents with cardiometabolic complications and those with metabolically healthy obesity? Pediatr Diabetes. (2018) 19:1147-55. doi: 10.1111/pedi.12694

45. de Winter M, Rioux BV, Boudreau JG, Bouchard DR, Senechal M. Physical activity and sedentary patterns among metabolically healthy individuals living with obesity. J Diabetes Res. (2018) 2018:7496768. doi: $10.1155 / 2018 / 7496768$

46. Lim HH. Sleep duration independently influences metabolic body size phenotype in children and adolescents: a population-based study. Sleep Med. (2018) 42:47-52. doi: 10.1016/j.sleep.2017.10.015

47. Gonzalez-Gil EM, Cadenas-Sanchez C, Santabarbara J, Bueno-Lozano G, Iglesia I, Gonzalez-Gross M, et al. Inflammation in metabolically healthy and metabolically abnormal adolescents: the HELENA study. Nutr Metab Cardiovasc Dis. (2018) 28:77-83. doi: 10.1016/j.numecd.2017.10.004

48. Khokhar A, Chin V, Perez-Colon S, Farook T, Bansal S, Kochummen $\mathrm{E}$, et al. Differences between metabolically healthy vs unhealthy obese children and adolescents. J Natl Med Assoc. (2017) 109:203-10. doi: 10.1016/j.jnma.2017.02.008

49. Yoon DY, Lee YA, Lee J, Kim JH, Shin CH, Yang SW. Prevalence and clinical characteristics of metabolically healthy obesity in Korean children and adolescents: data from the Korea National Health and Nutrition Examination Survey. J Korean Med Sci. (2017) 32:1840-7. doi: $10.3346 / \mathrm{jkms} .2017 .32 .11 .1840$

50. Elmaogullari S, Demirel F, Hatipoglu N. Risk factors that affect metabolic health status in obese children. J Pediatr Endocrinol Metab. (2017) 30:49-55. doi: 10.1515/jpem-2016-0128

51. Li L, Yin J, Cheng H, Wang Y, Gao S, Li M, et al. Identification of genetic and environmental factors predicting metabolically healthy obesity in children: data from the BCAMS study. J Clin Endocrinol Metab. (2016) 101:1816-25. doi: 10.1210/jc.2015-3760

52. Dalla Valle M, Laatikainen T, Kalliokoski T, Nykanen P, Jaaskelainen J. Childhood obesity in specialist care-searching for a healthy obese child. Ann Med. (2015) 47:639-54. doi: 10.3109/07853890.2015.1083118

53. Messiah SE, Arheart KL, Luke B, Lipshultz SE, Miller TL. Relationship between body mass index and metabolic syndrome risk factors among US 8- to 14-year-olds, 1999 to 2002. J Pediatr. (2008) 153:215-21. doi: 10.1016/j.jpeds.2008.03.002

54. Lambert M, Delvin EE, Levy E, O'Loughlin J, Paradis G, Barnett T, et al. Prevalence of cardiometabolic risk factors by weight status in a populationbased sample of Quebec children and adolescents. Can J Cardiol. (2008) 24:575-83. doi: 10.1016/S0828-282X(08)70639-1

55. Guerrero-Romero F, Aradillas-Garcia C, Simental-Mendia LE, TorresRodriguez ML, Mendoza Ede L, Rosales-Cervantes J, et al. Biochemical characteristics and risk factors for insulin resistance at different levels of obesity. Pediatrics. (2013) 131:e1211-7. doi: 10.1542/peds.2012-1421

56. Ding WQ, Yan YK, Zhang MX, Cheng H, Zhao XY, Hou DQ, et al. Hypertension outcomes in metabolically unhealthy normal-weight and 
metabolically healthy obese children and adolescents. J Hum Hypertens. (2015) 29:548-54. doi: 10.1038/jhh.2014.124

57. Rolland-Cachera MF, Deheeger M, Bellisle F, Sempe M, Guilloud-Bataille M, Patois E. Adiposity rebound in children: a simple indicator for predicting obesity. Am J Clin Nutr. (1984) 39:129-35. doi: 10.1093/ajcn/ 39.1.129

58. Nedelec R, Jokelainen J, Miettunen J, Ruokonen A, Herzig KH, Mannikko $\mathrm{M}$, et al. Early determinants of metabolically healthy obesity in young adults: study of the Northern Finland Birth Cohort 1966. Int J Obes. (2018) 42:1704-14. doi: 10.1038/s41366-018-0115-0

59. Amiel SA, Sherwin RS, Simonson DC, Lauritano AA, Tamborlane WV. Impaired insulin action in puberty. A contributing factor to poor glycemic control in adolescents with diabetes. $N$ Engl J Med. (1986) 315:215-9. doi: 10.1056/NEJM198607243150402

60. Roberge JB, Van Hulst A, Barnett TA, Drapeau V, Benedetti A, Tremblay A, et al. Lifestyle habits, dietary factors, and the metabolically unhealthy obese phenotype in youth. J Pediatr. (2019) 204:46-52.e1. doi: 10.1016/j.jpeds.2018.08.063

61. Kim JY, Tfayli H, Michaliszyn SF, Lee S, Arslanian S. Distinguishing characteristics of metabolically healthy versus metabolically unhealthy obese adolescent girls with polycystic ovary syndrome. Fertil Steril. (2016) 105:1603-11. doi: 10.1016/j.fertnstert.2016. 02.004

62. Lee S, Arslanian S. Body composition and cardiorespiratory fitness between metabolically healthy versus metabolically unhealthy obese black and white adolescents. J Adolesc Health. (2019) 64:327-32. doi: 10.1016/j.jadohealth.2018.08.024

63. Chun S, Lee S, Son HJ, Noh HM, Oh HY, Jang HB, et al. Clinical characteristics and metabolic health status of obese Korean children and adolescents. Korean J Fam Med. (2015) 36:233-8. doi: $10.4082 / \mathrm{kjfm} .2015 .36 .5 .233$

64. Thaiss CA, Levy M, Korem T, Dohnalova L, Shapiro H, Jaitin DA, et al. Microbiota diurnal rhythmicity programs host transcriptome oscillations. Cell. (2016) 167:1495-510.e12. doi: 10.1016/j.cell.2016. 11.003

65. Kelishadi R, Cook SR, Motlagh ME, Gouya MM, Ardalan G, Motaghian $\mathrm{M}$, et al. Metabolically obese normal weight and phenotypically obese metabolically normal youths: the CASPIAN study. J Am Diet Assoc. (2008) 108:82-90. doi: 10.1016/j.jada.2007.10.013

66. Kim SN, Kim J. Higher appendicular skeletal muscle mass protects metabolically healthy obese boys but not girls from cardiometabolic abnormality. Int J Environ Res Public Health. (2019) 16:652. doi: 10.3390/ijerph16040652

67. Suarez-Ortegon MF, Echeverri I, Prats-Puig A, Bassols J, Carreras-Badosa $\mathrm{G}$, Lopez-Bermejo A, et al. Iron status and metabolically unhealthy obesity in prepubertal children. Obesity. (2019) 27:636-44. doi: 10.1002/oby. 22425

68. Levy-Marchal C, Arslanian S, Cutfield W, Sinaiko A, Druet C, Marcovecchio $\mathrm{ML}$, et al. Insulin resistance in children: consensus, perspective, and future directions. J Clin Endocrinol Metab. (2010) 95:5189-98. doi: $10.1210 /$ jc.2010-1047

69. Ten S, Maclaren N. Insulin resistance syndrome in children. J Clin Endocrinol Metab. (2004) 89:2526-39. doi: 10.1210/jc.2004-0276

70. Edelstein SL, Knowler WC, Bain RP, Andres R, Barrett-Connor EL, Dowse GK, et al. Predictors of progression from impaired glucose tolerance to NIDDM: an analysis of six prospective studies. Diabetes. (1997) 46:701-10. doi: $10.2337 /$ diab.46.4.701

71. Saad MF, Knowler WC, Pettitt DJ, Nelson RG, Mott DM, Bennett $\mathrm{PH}$. The natural history of impaired glucose tolerance in the Pima Indians. N Engl J Med. (1988) 319:1500-6. doi: 10.1056/NEJM198812083 192302

72. Weiss R, Magge SN, Santoro N, Giannini C, Boston R, Holder T, et al. Glucose effectiveness in obese children: relation to degree of obesity and dysglycemia. Diabetes Care. (2015) 38:689-95. doi: 10.2337/dc14-2183

73. Elbein SC, Hasstedt SJ, Wegner K, Kahn SE. Heritability of pancreatic beta-cell function among nondiabetic members of Caucasian familial type 2 diabetic kindreds. J Clin Endocrinol Metab. (1999) 84:1398-403. doi: $10.1210 /$ jc. 84.4 .1398
74. Kahn SE. Clinical review 135: the importance of beta-cell failure in the development and progression of type 2 diabetes. J Clin Endocrinol Metab. (2001) 86:4047-58. doi: 10.1210/jcem.86.9.7713

75. Goran MI, Bergman RN, Avila Q, Watkins M, Ball GD, Shaibi GQ, et al. Impaired glucose tolerance and reduced beta-cell function in overweight Latino children with a positive family history for type 2 diabetes. J Clin Endocrinol Metab. (2004) 89:207-12. doi: 10.1210/jc.2003-0 31402

76. Bergman RN, Ader M, Huecking K, Van Citters G. Accurate assessment of beta-cell function: the hyperbolic correction. Diabetes. (2002) 51(Suppl. 1):S212-20. doi: 10.2337/diabetes.51.2007.S212

77. Arslanian SA, Bacha F, Saad R, Gungor N. Family history of type 2 diabetes is associated with decreased insulin sensitivity and an impaired balance between insulin sensitivity and insulin secretion in white youth. Diabetes Care. (2005) 28:115-9. doi: 10.2337/diacare.28.1.115

78. de Luca C, Olefsky JM. Inflammation and insulin resistance. FEBS Lett. (2008) 582:97-105. doi: 10.1016/j.febslet.2007.11.057

79. Hotamisligil GS. Inflammation and metabolic disorders. Nature. (2006) 444:860-7. doi: 10.1038/nature 05485

80. Lumeng CN, Saltiel AR. Inflammatory links between obesity and metabolic disease. J Clin Invest. (2011) 121:2111-7. doi: 10.1172/JCI57132

81. Reilly SM, Saltiel AR. Adapting to obesity with adipose tissue inflammation. Nat Rev Endocrinol. (2017) 13:633-43. doi: 10.1038/nrendo.2017.90

82. Kershaw EE, Flier JS. Adipose tissue as an endocrine organ. J Clin Endocrinol Metab. (2004) 89:2548-56. doi: 10.1210/jc.2004-0395

83. Gustafson B, Hammarstedt A, Andersson CX, Smith U. Inflamed adipose tissue: a culprit underlying the metabolic syndrome and atherosclerosis. Arterioscler Thromb Vasc Biol. (2007) 27:2276-83. doi: 10.1161/ATVBAHA.107.147835

84. Li P, Liu S, Lu M, Bandyopadhyay G, Oh D, Imamura T, et al. Hematopoieticderived galectin-3 causes cellular and systemic insulin resistance. Cell. (2016) 167:973-84.e12. doi: 10.1016/j.cell.2016.10.025

85. Li P, Oh DY, Bandyopadhyay G, Lagakos WS, Talukdar S, Osborn O, et al. LTB4 promotes insulin resistance in obese mice by acting on macrophages, hepatocytes and myocytes. Nat Med. (2015) 21:239-47. doi: $10.1038 / \mathrm{nm} .3800$

86. Lu YC, Yeh WC, Ohashi PS. LPS/TLR4 signal transduction pathway. Cytokine. (2008) 42:145-51. doi: 10.1016/j.cyto.2008.01.006

87. McLaughlin T, Liu LF, Lamendola C, Shen L, Morton J, Rivas H, et al. Tcell profile in adipose tissue is associated with insulin resistance and systemic inflammation in humans. Arterioscler Thromb Vasc Biol. (2014) 34:2637-43. doi: 10.1161/ATVBAHA.114.304636

88. Nishimura S, Manabe I, Nagasaki M, Eto K, Yamashita H, Ohsugi $\mathrm{M}$, et al. CD8+ effector $\mathrm{T}$ cells contribute to macrophage recruitment and adipose tissue inflammation in obesity. Nat Med. (2009) 15:914-20. doi: $10.1038 / \mathrm{nm} .1964$

89. Yang H, Youm YH, Vandanmagsar B, Ravussin A, Gimble JM, Greenway F, et al. Obesity increases the production of proinflammatory mediators from adipose tissue $\mathrm{T}$ cells and compromises TCR repertoire diversity: implications for systemic inflammation and insulin resistance. J Immunol. (2010) 185:1836-45. doi: 10.4049/jimmunol.1000021

90. Stefan N, Schick F, Haring HU. Causes, characteristics, and consequences of metabolically unhealthy normal weight in humans. Cell Metab. (2017) 26:292-300. doi: 10.1016/j.cmet.2017.07.008

91. Karpe F, Pinnick KE. Biology of upper-body and lower-body adipose tissuelink to whole-body phenotypes. Nat Rev Endocrinol. (2015) 11:90-100. doi: 10.1038/nrendo.2014.185

92. van der Zijl NJ, Goossens GH, Moors CC, van Raalte DH, Muskiet $\mathrm{MH}$, Pouwels PJ, et al. Ectopic fat storage in the pancreas, liver, and abdominal fat depots: impact on $\beta$-cell function in individuals with impaired glucose metabolism. J Clin Endocrinol Metab. (2011) 96:459-67. doi: 10.1210/jc.2010-1722

93. Kotronen A, Seppälä-Lindroos A, Bergholm R, Yki-Järvinen H. Tissue specificity of insulin resistance in humans: fat in the liver rather than muscle is associated with features of the metabolic syndrome. Diabetologia. (2008) 51:130-8. doi: 10.1007/s00125-007-0867-x

94. Stefan N, Häring HU, Hu FB, Schulze MB. Metabolically healthy obesity: epidemiology, mechanisms, and clinical implications. Lancet 
Diabetes Endocrinol. (2013) 1:152-62. doi: 10.1016/S2213-8587(13) 70062-7

95. Stefan N, Häring HU, Cusi K. Non-alcoholic fatty liver disease: causes, diagnosis, cardiometabolic consequences, and treatment strategies. Lancet Diabetes Endocrinol. (2019) 7:313-24. doi: 10.1016/S2213-8587(18)30154-2

96. Targher G, Lonardo A, Byrne CD. Nonalcoholic fatty liver disease and chronic vascular complications of diabetes mellitus. Nat Rev Endocrinol. (2018) 14:99-114. doi: 10.1038/nrendo.2017.173

97. Zhang M, Hu T, Zhang S, Zhou L. Associations of different adipose tissue depots with insulin resistance: a systematic review and meta-analysis of observational studies. Sci Rep. (2015) 5:18495. doi: 10.1038/srep18495

98. Chen P, Hou X, Hu G, Wei L, Jiao L, Wang H, et al. Abdominal subcutaneous adipose tissue: a favorable adipose depot for diabetes? Cardiovasc Diabetol. (2018) 17:93. doi: 10.1186/s12933-018-0734-8

99. Fabbrini E, Magkos F, Mohammed BS, Pietka T, Abumrad NA, Patterson $\mathrm{BW}$, et al. Intrahepatic fat, not visceral fat, is linked with metabolic complications of obesity. Proc Natl Acad Sci USA. (2009) 106:15430-5. doi: $10.1073 /$ pnas. 0904944106

100. Kim JY, van de Wall E, Laplante M, Azzara A, Trujillo ME, Hofmann $\mathrm{SM}$, et al. Obesity-associated improvements in metabolic profile through expansion of adipose tissue. J Clin Invest. (2007) 117:2621-37. doi: $10.1172 /$ JCI31021

101. Kondo H, Shimomura I, Matsukawa Y, Kumada M, Takahashi M, Matsuda $\mathrm{M}$, et al. Association of adiponectin mutation with type 2 diabetes: a candidate gene for the insulin resistance syndrome. Diabetes. (2002) 51:2325-8. doi: 10.2337/diabetes.51.7.2325

102. Kadowaki T, Yamauchi T. Adiponectin and adiponectin receptors. Endocr Rev. (2005) 26:439-51. doi: 10.1210/er.2005-0005

103. You T, Nicklas BJ. Effects of exercise on adipokines and the metabolic syndrome. Curr Diab Rep. (2008) 8:7-11. doi: 10.1007/s11892-008-0003-4

104. Klünder-Klünder M, Flores-Huerta S, García-Macedo R, Peralta-Romero J, Cruz M. Adiponectin in eutrophic and obese children as a biomarker to predict metabolic syndrome and each of its components. BMC Public Health. (2013) 13:88. doi: 10.1186/1471-2458-13-88

105. Rabe K, Lehrke M, Parhofer KG, Broedl UC. Adipokines and insulin resistance. Mol Med. (2008) 14:741-51. doi: 10.2119/2008-00058.Rabe

106. Buyukinan M, Atar M, Can U, Pirgon O, Guzelant A, Deniz I. The association between serum vaspin and omentin-1 levels in obese children with metabolic syndrome. Metab Syndr Relat Disord. (2018) 16:76-81. doi: 10.1089/met.2017.0133

107. Longo M, Zatterale F, Naderi J, Parrillo L, Formisano P, Raciti GA, et al. Adipose tissue dysfunction as determinant of obesity-associated metabolic complications. Int J Mol Sci. (2019) 20:E2358. doi: 10.3390/ijms20092358

108. Rutkowski JM, Stern JH, Scherer PE. The cell biology of fat expansion. J Cell Biol. (2015) 208:501-12. doi: 10.1083/jcb.201409063

109. Lefterova MI, Haakonsson AK, Lazar MA, Mandrup S. PPAR $\gamma$ and the global map of adipogenesis and beyond. Trends Endocrinol Metab. (2014) 25:293-302. doi: 10.1016/j.tem.2014.04.001

110. Odegaard JI, Ricardo-Gonzalez RR, Red Eagle A, Vats D, Morel CR, Goforth MH, et al. Alternative M2 activation of Kupffer cells by PPARdelta ameliorates obesity-induced insulin resistance. Cell Metab. (2008) 7:496-507. doi: 10.1016/j.cmet.2008.04.003

111. Roberts R, Hodson L, Dennis AL, Neville MJ, Humphreys SM, Harnden KE, et al. Markers of de novo lipogenesis in adipose tissue: associations with small adipocytes and insulin sensitivity in humans. Diabetologia. (2009) 52:882-90. doi: 10.1007/s00125-009-1300-4

112. Nguyen P, Leray V, Diez M, Serisier S, Le Bloc'h J, Siliart B, et al. Liver lipid metabolism. J Anim Physiol Anim Nutr. (2008) 92:272-83. doi: $10.1111 / j .1439-0396.2007 .00752 . x$

113. Dongiovanni P, Stender S, Pietrelli A, Mancina RM, Cespiati A, Petta S, et al. Causal relationship of hepatic fat with liver damage and insulin resistance in nonalcoholic fatty liver. J Intern Med. (2018) 283:356-70. doi: 10.1111/joim.12719

114. Nobili V, Alisi A, Valenti L, Miele L, Feldstein AE, Alkhouri N. NAFLD in children: new genes, new diagnostic modalities and new drugs. Nat Rev Gastroenterol Hepatol. (2019) 16:517-30. doi: 10.1038/s41575-019-0169-z

115. Stefan N, Häring HU. The role of hepatokines in metabolism. Nat Rev Endocrinol. (2013) 9:144-52. doi: 10.1038/nrendo.2012.258
116. Watt MJ, Miotto PM, De Nardo W, Montgomery MK. The liver as an endocrine organ-linking NAFLD and insulin resistance. Endocr Rev. (2019) 40:1367-93. doi: 10.1210/er.2019-00034

117. Galbo T, Shulman GI. Lipid-induced hepatic insulin resistance. Aging. (2013) 5:582-3. doi: 10.18632/aging.100585

118. Higgins V, Adeli K. Pediatric metabolic syndrome: pathophysiology and laboratory assessment. EJIFCC. (2017) 28:25-42.

119. Petersen MC, Shulman GI. Roles of diacylglycerols and ceramides in hepatic insulin resistance. Trends Pharmacol Sci. (2017) 38:649-65. doi: 10.1016/j.tips.2017.04.004

120. Targher G, Byrne CD, Lonardo A, Zoppini G, Barbui C. Non-alcoholic fatty liver disease and risk of incident cardiovascular disease: a meta-analysis. $J$ Hepatol. (2016) 65:589-600. doi: 10.1016/j.jhep.2016.05.013

121. European Association for the Study of the Liver (EASL), European Association for the Study of Diabetes (EASD), European Association for the Study of Obesity (EASO). EASL-EASD-EASO Clinical Practice Guidelines for the management of non-alcoholic fatty liver disease. J Hepatol. (2016) 64:1388-402. doi: 10.1016/j.jhep.2015.11.004

122. Turcot V, Lu Y, Highland HM, Schurmann C, Justice AE, Fine RS, et al. Protein-altering variants associated with body mass index implicate pathways that control energy intake and expenditure in obesity. Nat Genet. (2018) 50:26-41. doi: 10.1038/s41588-018-0082-3

123. Locke AE, Kahali B, Berndt SI, Justice AE, Pers TH, Day FR, et al. Genetic studies of body mass index yield new insights for obesity biology. Nature. (2015) 518:197-206. doi: 10.1038/nature14177

124. Sung YJ, Pérusse L, Sarzynski MA, Fornage M, Sidney S, Sternfeld $B$, et al. Genome-wide association studies suggest sex-specific loci associated with abdominal and visceral fat. Int J Obes. (2016) 40:662-74. doi: 10.1038/ijo.2015.217

125. Kilpeläinen TO, Carli JF, Skowronski AA, Sun Q, Kriebel J, Feitosa MF, et al. Genome-wide meta-analysis uncovers novel loci influencing circulating leptin levels. Nat Commun. (2016) 7:10494. doi: 10.1038/ncomms10494

126. Kilpeläinen TO, Zillikens MC, Stančákova A, Finucane FM, Ried JS, Langenberg C, et al. Genetic variation near IRS1 associates with reduced adiposity and an impaired metabolic profile. Nat Genet. (2011) 43:753-60. doi: $10.1038 /$ ng.866

127. Lu Y, Day FR, Gustafsson S, Buchkovich ML, Na J, Bataille V, et al. New loci for body fat percentage reveal link between adiposity and cardiometabolic disease risk. Nat Commun. (2016) 7:10495. doi: 10.1038/ncomms 10495

128. Loos RJF, Kilpeläinen TO. Genes that make you fat, but keep you healthy. $J$ Intern Med. (2018) 284:450-63. doi: 10.1111/joim.12827

129. Simmonds M, Llewellyn A, Owen CG, Woolacott N. Predicting adult obesity from childhood obesity: a systematic review and meta-analysis. Obes Rev. (2016) 17:95-107. doi: 10.1111/obr.12334

130. Aguilar-Salinas CA, Garcia EG, Robles L, Riano D, Ruiz-Gomez DG, GarciaUlloa AC, et al. High adiponectin concentrations are associated with the metabolically healthy obese phenotype. J Clin Endocrinol Metab. (2008) 93:4075-9. doi: 10.1210/jc.2007-2724

131. Bouhours-Nouet N, Dufresne S, de Casson FB, Mathieu E, Douay O, Gatelais F, et al. High birth weight and early postnatal weight gain protect obese children and adolescents from truncal adiposity and insulin resistance: metabolically healthy but obese subjects? Diabetes Care. (2008) 31:1031-6. doi: $10.2337 / \mathrm{dc} 07-1647$

132. McLaughlin T, Deng A, Yee G, Lamendola C, Reaven G, Tsao PS, et al. Inflammation in subcutaneous adipose tissue: relationship to adipose cell size. Diabetologia. (2010) 53:369-77. doi: 10.1007/s00125-009-1496-3

133. Westerbacka J, Corner A, Kannisto K, Kolak M, Makkonen J, Korsheninnikova E, et al. Acute in vivo effects of insulin on gene expression in adipose tissue in insulin-resistant and insulin-sensitive subjects. Diabetologia. (2006) 49:132-40. doi: 10.1007/s00125-005-0075-5

134. Zhao M, Lopez-Bermejo A, Caserta CA, Medeiros CCM, Kollias A, Bassols J, et al. Metabolically healthy obesity and high carotid intimamedia thickness in children and adolescents: international childhood vascular structure evaluation consortium. Diabetes Care. (2019) 42:119-25. doi: $10.2337 / \mathrm{dc} 18-1536$

135. Selvakumar PKC, Kabbany MN, Lopez R, Alkhouri N. Prevalence and risk factors of nonalcoholic fatty liver disease in metabolically healthy 
obese adolescents in the United States: an analysis of national health and nutrition examination survey data. J Hepatol. (2017) 66:S587-8. doi: 10.1016/S0168-8278(17)31601-X

136. Stefan N, Haring HU, Schulze MB. Metabolically healthy obesity: the low-hanging fruit in obesity treatment? Lancet Diabetes Endocrinol. (2018) 6:249-58. doi: 10.1016/S2213-8587(17) 30292-9

137. Haufe S, Haas V, Utz W, Birkenfeld AL, Jeran S, Bohnke J, et al. Long-lasting improvements in liver fat and metabolism despite body weight regain after dietary weight loss. Diabetes Care. (2013) 36:3786-92. doi: $10.2337 / \mathrm{dc} 13-0102$
Conflict of Interest: The authors declare that the research was conducted in the absence of any commercial or financial relationships that could be construed as a potential conflict of interest.

Copyright $\odot 2019$ Vukovic, Dos Santos, Ybarra and Atar. This is an open-access article distributed under the terms of the Creative Commons Attribution License (CC $B Y)$. The use, distribution or reproduction in other forums is permitted, provided the original author(s) and the copyright owner(s) are credited and that the original publication in this journal is cited, in accordance with accepted academic practice. No use, distribution or reproduction is permitted which does not comply with these terms. 